\title{
Turismo nas cidades gêmeas de fronteira e as possibilidades da Lei 12.723/2012
}

\section{Tourism in twin border cities and the possibilities of Brazilian Law n. 12.723/2012}

Rosa Barros Ferreira Almeida, Edgar Aparecido da Costa, Milton Augusto Pasquotto Mariani, Alejandro Gabriel Benedetti

\section{RESUMO}

Neste trabalho, a fronteira é vista como espaço de comunicação e de trocas promovidas por fortes interações que desconsideram o limite internacional e são caracterizadas por intercâmbios nas mais diversas áreas, sobretudo, no comércio. As localidades fronteiriças apresentam vários elementos que interessam e atraem turistas, desde aqueles produzidos pela construção histórica de seus territórios (sociedade e cultura) até aqueles de conformação natural e econômica, especialmente o comércio. As vantagens de aquisição de mercadorias em uma das bandas territoriais componentes da fronteira são importantes indutoras do turismo. Nessa perspectiva das vantagens comerciais, administrações governamentais e empresariais têm elaborado inúmeros artifícios para atrair turistas para essas regiões. Dentre esses artifícios, está a Lei $12.723 / 2012$ do governo federal brasileiro que autoriza a instalação de free shop nas cidades gêmeas. Este trabalho objetiva, pois, analisar como os agentes territoriais de uma cidade gêmea percebem a possibilidade de implantação desta Lei e se isso pode fortalecer o turismo de fronteira. Para tanto, foram realizados levantamentos de dados primários, através de entrevistas semiestruturadas visando obter informações sobre como os agentes territoriais da fronteira Brasil/Bolívia receberam a Lei dos Free Shops. A análise dos dados corrobora a afirmativa de que, dentre os benefícios alcançados, destaca-se o fortalecimento da concorrência entre estabelecimentos instalados no Brasil e na Bolívia com foco em produtos importados. A implantação do Free Shop em Corumbá não fará com que o turista/fronteiriço deixe de frequentar a Bolívia por razões como procura por baixos preços, variedade de produtos e, sobretudo, pela oportunidade de aproximação da diversidade cultural.

PALAVRAS-CHAVE: Fronteira; Turismo; Free Shop. 


\section{ABSTRACT}

In this study, the border is seen as a space of communication and exchanges promoted by strong interactions that disregard the international limit and are characterized by exchanges in the most diverse areas, especially in commerce. Frontier localities present several elements that interest and attract tourists, from those produced by the historical construction of their territories (society and culture) to those of natural and economic conformation, especially commerce. The advantages of purchasing goods in one of the towns components of the frontier are important boosts of tourism. In the perspective of the commercial advantages, governmental and business administrations have elaborated numerous devices to attract tourists to these regions. Among these devices, there is the Law $\mathrm{n}$. $12.723 / 2012$ of the Brazilian federal government that authorizes the installation of free shops in the twin cities. This study aims, therefore, to analyze how the territorial agents of a twin city perceive the possibility of implementation of this Law and if this can strengthen the frontier tourism. For this purpose, primary data were collected through semi-structured interviews to obtain information about how the territorial agents of the Brazil/Bolivia border received the Free Shops Law. The analysis of the data corroborates the affirmation that, among the benefits achieved, it is worth highlighting the strengthening of competition between establishments located in Brazil and in Bolivia with focus on imported products. The establishment of the Free Shop in Corumbá will not cause the tourist/frontier to stop attending Bolivia for reasons such as low prices, variety of products and, above all, the opportunity to approach cultural diversity.

KEYWORDS: Border; Tourism; Free Shop.

\section{Introdução}

A visão cotidiana de moradores fronteiriços atravessando a linha internacional a fim de realizarem compras em ambos os territórios limítrofes quase sempre evoca uma noção de normalidade aos olhos dos cidadãos e das cidadãs envolvidos nessas tramas locais. Contudo, há racionalidades diversas que orientam as mobilidades humanas: motivações particulares e induções das coletividades.

A partir do momento que se passa a vivenciar a fronteira, a dinâmica do território é modificada (COSTA, 2009). Por isso, acabam por assumir uma abrangência maior, pois, mesmo respeitando a soberania dos países limítrofes, as sociedades fronteiriças buscam arranjos territoriais para seus problemas e potencialidades.

As políticas públicas do governo central, quando implantadas nos territórios fronteiriços, podem ser portadoras de harmonias ou tensões nas escalas locais. Invariavelmente, quando o interesse é econômico, as territorialidades provocam tensões territoriais. Como exemplo podem ser citadas as mobilizações ocorridas nas fronteiras Brasil/Bolívia e Brasil/Paraguai, em março de 2015, simplesmente pelo anúncio da redução 
do limite de US\$300 para US\$150 para os gastos no exterior com isenção de Imposto de Importação apenas para o lado brasileiro dessas fronteiras.

Numa perspectiva de ampliação de vantagens comerciais competitivas das cidades brasileiras fronteiriças, foi homologada a Lei 12.723/2012, que autoriza a instalação de lojas francas em municípios contíguos da linha de fronteira do Brasil, cujas sedes se caracterizam como cidades gêmeas, como é o caso de Corumbá-MS. No Brasil, os Free Shops ou duty free são lojas onde os produtos são vendidos com diminuição ou completa isenção de impostos. Normalmente se localizam em portos ou aeroportos.

As dinâmicas territoriais num espaço fronteiriço são mediadas pelas normativas de cada território que a forma. Contudo, quando se planeja o turismo de fronteira como possibilidade de desenvolvimento é necessário "existir um processo de integração entre dois ou mais territórios e/ou sociedades, sendo o turismo parte significativa dessa integração" (PAIXÃO, 2006, p.72). Ressalta-se que não é o caso da política pública de permissão para implantação de estabelecimentos livres de impostos de importação no lado brasileiro da fronteira onde estão materializadas as cidades gêmeas.

Por essa razão, torna-se imprescindível analisar as possibilidades da Lei dos Free Shops para o desenvolvimento territorial, entendido por Dallabrida (2007, p.51) "como um processo de mudança estrutural empreendido por uma sociedade organizada territorialmente, sustentado na potencialização dos capitais e recursos (materiais e imateriais) existentes no local'.

Assim, o objetivo do trabalho é analisar como os agentes territoriais de uma cidade gêmea fronteiriça percebem a possibilidade de implantação dessa Lei e se isso pode fortalecer o turismo na fronteira.

O trabalho está organizado em quatro seções. As duas primeiras procuram oferecer uma discussão teórica e situar o leitor para as questões relacionadas ao tripé turismo, território e fronteira, bem como a alguns estudos sobre Free Shops nas fronteiras brasileiras. Optou-se por apresentar os procedimentos da pesquisa na terceira seção a fim de estar próxima dos resultados e discussão (quarta seção), favorecendo o entendimento da origem das informações e da forma de sua obtenção.

\section{Turismo, território e fronteira}

Discorrer sobre turismo e território é, sobretudo, mencionar a importância de ambos para o estudo do melhor aproveitamento das possibilidades das fronteiras. São, pelo menos, dois territórios nacionais de cada lado, marcados por diferentes potencialidades, leis, costumes e identidades. Logo, abordar o turismo sob a ótica das fronteiras é considerar novas territorialidades, dos lugares, em especial no cotidiano fronteiriço, que tem o comércio como uma das atividades principais (feiras livres, lojas, mercados e restaurantes), sendo altamente influenciado pelas oscilações cambiais. 
Assim, adota-se o pressuposto teórico de Banducci Junior (2014, p.10) para quem "as fronteiras compreendem redes de relações e de influências sociais, culturais e políticas que transcendem os espaços locais para abranger contextos nacionais e internacionais mais amplos". Do mesmo modo, o turismo, na medida em que propicia o contato entre distintas culturas, promove o encontro e o diálogo entre identidades, cria ambientes de negociações e de conflitos sociais, além de resistência e confrontos políticos que advêm de condições históricas internas. Centra-se, também, nas contradições colocadas pela situação de contato entre sociedades e culturas diversas.

Beltrão (1999) apresenta uma visão abrangente da atividade e contribui significativamente com a proposta desse trabalho ao afirmar que 0 turismo é o conjunto de todas as atividades sociais, culturais, políticas, econômicas e naturais responsáveis pelo deslocamento de pessoas de sua origem em busca de outros destinos desconhecidos ou não, com uma permanência temporária. Ao mencionar a política e a economia como parte formadora das atividades turísticas, automaticamente abre-se um leque de ações inerentes aos governos em suas diversas esferas administrativas, essencialmente a municipal. Conforme Dias (2005), os municípios representam a base local da atividade, devendo exercer, entre suas principais funções, o acompanhamento do desenvolvimento do turismo, tomando providências para que os atrativos turísticos sejam monitorados e utilizados de forma a efetivar a exploração sustentável.

Por se ter no turismo significativas afinidades com outras atividades humanas, uma vez que, no senso comum, é confundido com tipos de lazer ou ligado a viagens, para conceituá-lo faz-se necessário estabelecer uma distinção entre turismo e viagem. Turismo, segundo Coriolano e Silva (2005, p.42-43) "é um fenômeno dos tempos modernos [...] é uma invenção do capitalismo"; enquanto viagem pode ser entendida como uma atividade que sempre existiu desde a origem do homem, ocorrendo para atender as mais diversas necessidades, desde a de sobrevivência até a de celebração de ritos sagrados para "louvar os deuses".

Conforme Coriolano e Silva (2005), a dimensão da atividade do turismo excede o setor econômico, por essa razão são apresentadas diferentes definições para os termos turista e turismo. Do ponto de vista do negócio, o turista é o hóspede, o consumidor, o cliente e, desse modo, o turismo é uma fonte de renda e de divisas. Do ponto de vista sociocultural, o turista é um visitante importante em contato com o território, com a cultura e com o cotidiano dos residentes. Nesse sentido, o turismo é uma prática social, que reúne oportunidades de vivência cultural, troca de experiências, realização de sonhos, busca de emoções e formas de aprendizagem. Em outras palavras, "é um negócio econômico para aqueles que vendem e uma oportunidade de aprendizagem para os que o fazem" (CORIOLANO; SILVA, 2005, p. 62).

A perspectiva territorial de tratamento do turismo justifica-se pela sua ocorrência no território, isto considerando o deslocamento do turista até o local de produção e de consumo que geram transformações na dinâmica 
local, quer sejam relacionados à infraestrutura do lugar (equipamentos hoteleiros, de restauração, estruturas de acesso, de saneamento, entre outras), quer sejam através das relações travadas entre turistas e residentes (LEITE, 2008, p. 44).

Para Saquet (2013, p. 118), "o território é o lugar de relações sociais, de conexões e de redes"; de vida para além da produção econômica como natureza, apropriação, mudanças, mobilidade, identidade, patrimônio cultural; como produto socioespacial e condição para o habitar, para o viver e para o produzir. A fronteira, percebida como uma construção simbólica, mesmo em sua configuração geopolítica, define o limite de territórios, mas compreende ainda a definição de territorialidades, que se estabelecem mediante relações de complementariedade transfronteiriça, face a sua condição de liminaridade, de esfera de contato entre diferentes culturas (COSTA, 2011).

Considerando que, para diversos autores, a definição de território está associada à noção de poder, Dallabrida (2007, p. 52) destaca que o poder precisa ser concebido na sua dimensão multidimensional, pois o Estado não é o único ator capaz de determinar os processos sobre o território. Insere-se, então, nesse cenário, o poder da sociedade civil e do mercado.

Haesbaert (2007, p.22) considera que os territórios se firmam através da territorialidade que, além de incorporar uma dimensão mais estritamente política, diz respeito, também, às relações econômicas e às culturais, pois está "intimamente ligada ao modo como as pessoas utilizam a terra, como elas próprias se organizam no espaço e como elas dão significado ao lugar".

Para Sack (1986, p. 219), imbuída de significação, "a territorialidade, como um componente do poder, não é apenas um meio para criar e manter a ordem, mas é uma estratégia para criar e manter grande parte do contexto geográfico através do qual nós experimentamos o mundo e o dotamos de significado". Embora "as ações, os jogos de forças, as lutas, os fluxos, as ideologias, as normas que compõem o território" nem sempre possam ser vistas, são sentidas e respeitadas (COSTA, 2009, p.63). A título de exemplificação, nos territórios das gangues, dos traficantes, das milícias, mesmo sem ter uma regulamentação materializada em formato de Lei, seus códigos são respeitados e obedecidos pelos seus componentes.

Mariani e Fischer (2014), numa abordagem introdutória, afirmam que as territorialidades podem ser definidas como a síntese das relações sociais que dão corpo e conferem função ao território. A territorialidade é, ao mesmo tempo, um produto da vontade individual e da coletiva. São indivíduos, empresas e Estados que exercem suas territorialidades sobre determinado espaço geográfico impondo suas vontades e virtudes (Costa, 2009). Nas palavras de Mariani (2010), "cada um, face às suas respectivas territorialidades que conferem distintas funções aos territórios, Ihe emprestam uma dinâmica de desenvolvimento particular, algumas mais integrativas; outras mais excludentes".

Nessa dinâmica, na tentativa do governo federal de integrar o comércio entre os países vizinhos, o turismo vem como uma alternativa 
multiplicadora dessa integração, ou seja, "a fronteira representa para o turismo uma oportunidade de promover um processo de integração" (COSTA, FIGUEIREDO, SILVA, 2010, p.42). Nesse ponto, o turismo de fronteira proporciona interações entre diversas nacionalidades, envolvendo estudantes, pesquisadores, músicos, curiosos, além de promover lazer, shows e eventos. E os turistas de fato, que procuram essas localidades por diversas razões, entre as quais, explorar a fauna e a flora locais, atração pelo contraste cultural ou, até mesmo, pela curiosidade de conhecer um território fronteiriço.

Alves, Ferraz e Oliveira (2011, p. 185) afirmam que "os pacotes turísticos de fronteira acabam envolvendo atividades nos vários países que compartilham um limite". Considerando limite como linha imaginária que separa territórios, nas palavras de Paixão (2006), ainda que em determinadas fronteiras sejam visíveis quaisquer simbologias (marco), normativas (leis) ou artificialidades (placas) que exaltem a divisão entre Estados, os turistas devem senti-las como uma para o fazer turístico.

O conceito de fronteira aqui adotado está relacionado ao espaço de comunicação e de trocas, pois estão deixando de ser vistos como um "espaço que separa". Trata-se de lugar de reflexão e de integração, de aproximações culturais diversas. Conforme afirma, Oliveira (2009, p.69) "as fronteiras são os elos mais firmes de aproximação entre os povos".

De acordo com Castello (1995), uma das características dos espaços de fronteira é a dupla condição de separação e encontro. Seja pela necessidade de se estabelecer separações e limites em nome da diferença cultural e da preservação da soberania nacional, seja pelas práticas sociais e trocas que se estabelecem face à proximidade física e interesses comuns. "A fronteira é, a um só tempo, área de separação e de aproximação, linha de barreira e espaço polarizador. É, sobretudo, um espaço de tensões, de coexistência das diferenças, e do estabelecimento de novas realidades socioculturais" (CASTELLO, 1995, p.18).

Costa, Figueiredo e Silva (2010) ressaltam que tal diversidade, aliada a excentricidade e a especificidade que são características da fronteira, gera uma atividade turística dinâmica nessas regiões. O fluxo turístico proporciona aos turistas, integração às práticas comerciais e às econômicas da localidade.

Em seu trabalho Turismo e paisagem cultural: para pensar 0 transfronteiriço, Costa (2011) afirma que devido a crescente importância que a temática de fronteiras vem assumindo nos últimos anos, elas se transformaram em objetos específicos de preocupação governamental, fato que deu origem ao Projeto de Promoção ao Desenvolvimento da Faixa de Fronteira - PDFF, concebido pelo Ministério da Integração Nacional, dentro da Política Nacional de Desenvolvimento Regional, voltada aos espaços subregionais, buscando a dinamização econômica, o fornecimento da infraestrutura social e produtiva, bem como a melhoria nas condições de cidadania, envolvendo o fortalecimento dos atores e aproveitamento das particularidades locais (BRASIL, 2009). 
Considerando a potencialidade da atividade turística no desenvolvimento das áreas de fronteira, o Governo Federal assumiu o turismo como um dos vetores de ampliação a ser estimulado nas áreas fronteiriças, já que a atividade apresenta importante papel na valorização de territórios, ao agregar valor a determinados elementos ignorados pelas demais forças produtivas locais (CASTROGIOVANNI, 2003).

Um dos maiores desafios do PDFF é difundir a nova concepção a respeito das áreas de fronteira e suas potencialidades, numa perspectiva de que são regiões com singularidades capazes de atrair visitantes que buscam o contato com o outro, na expectativa de vivenciar o lugar, com toda a carga simbólica que tornam os lugares de fronteira propícios às práticas turísticas (COSTA, 2011).

Em se tratando, particularmente, das manifestações do turismo em áreas fronteiriças, Paixão (2006) aponta três situações que representam distintos quadros quanto ao planejamento e demais políticas que visem fortalecer o turismo no panorama sul-americano: o turismo pela fronteira, na fronteira e de fronteira.

Segundo ele, o turismo pela fronteira está relacionado à percepção de fronteira enquanto limite entre dois ou mais territórios e, por isso mesmo, dotada de aparatos de segurança, de militarização e de exigências burocráticas (passaportes, vistos de entrada, etc.) que tornam o fluxo turístico moroso.

O turismo na fronteira é a tipologia empregada para as fronteiras que, mesmo conformando uma paisagem aparentemente homogênea, com atrativos turísticos dispersos em dois territórios nacionais, sob o ponto de vista turístico não podem ser apropriadas em sua plenitude para implantação de produtos e roteiros. Entre as razões principais para o fato, situa-se a relativa ausência do Estado num dos territórios, fazendo com que o turismo se incline a especializar-se unilateralmente em determinadas fronteiras, dificultando, assim, o processo de turistificação binacional.

Já o turismo de fronteira, segundo Paixão (2006, p.98), é uma proposta direcionada às áreas em que "a fronteira é parte indissociável do destino de visitação e, por isto, configura-se numa região de planejamento turístico internacionaf", considerando que o estabelecimento de demarcações territoriais pode ficar mascarado pela contiguidade e pela homogeneidade paisagística.

Não se pode esquecer que a mobilidade humana (dos quais os fluxos turísticos constituem uma componente), as tipologias de relações políticas que envolvem os fluxos turísticos transfronteiriços e as parcerias turísticas, incluindo suas particularidades, são elementos importantes a serem considerados na estruturação do turismo em áreas de fronteira (SOFIELD, 2006).

As possibilidades de compras pela variação cambial são elementos muito fortes para estimular o turismo nas áreas de fronteira. Segundo Oliveira (2005, p.76), "o ato de comprar faz parte da necessidade de satisfação pessoal do turista. É uma questão psicológica”. Quem realiza uma 
viagem, dificilmente voltará de mãos vazias, pois há forte tendência em trazer consigo, na bagagem, algum elemento adquirido nos locais visitados. Logo, "se o local visitado oferece mercadorias com qualidade, preços convidativos e que não são encontráveis na cidade de residência do turista, então este local vai beneficiar-se extraordinariamente" (OLIVEIRA, 2005, p.76).

Os Free Shop's como indutores do turismo para as fronteiras

Os estabelecimentos do tipo Duty Free ou Free Shop, normalmente instalados em portos, aeroportos e navios para viagens internacionais, caracterizam-se pela não incidência de tributos sobre os produtos por eles comercializados, de regra importados. Amaral (2008, p.16) afirma que é um dos locais de grande busca do turista, funcionando como um dos últimos destinos obrigatórios em que se deve visitar antes de retornar ao país que reside, desde que se considere 0 ato de comprar nesses estabelecimentos como um dos requisitos para que a experiência turística seja completa. Assim, o uso das taxas livres de impostos o torna atraente, porém pode-se inferir que "o ato de comprar" está intimamente ligado à ideia de completude da viagem.

Allis (2008) assegura que, no caso de turismo de compras, o processo de produção envolve peculiaridades que merecem ser destacadas, posto que a composição entre oferta original (basicamente recursos naturais e culturais) e a oferta técnica (serviços de apoio e facilidade em geral) se estruturam de maneira diferente do que em destinos de lazer:

O turismo de compras, a princípio, prescinde de atributos paisagísticos exclusivos ou de destaque, e foca-se nas conveniências da condição do local visitado. Assim, a rigor, turismo de compras é um segmento possível a qualquer destino turístico, de forma que o fluxo de turistas pode ser esperado a partir de políticas de incentivos legais e fiscais. Ou seja, turismo de compras é apenas mais um resultado de políticas de desenvolvimento de fronteiras, que pode ser interpretado no âmbito das estratégias de ocupação de fronteiras por conta de segurança nacional, desconcentração econômica e populacional e efetivação de potencialidades regionais (ALLIS, 2008, p.9).

Acerca do turismo de compras em cidades de fronteira no Brasil, que são relativamente bem estruturadas e dependentes dessa atividade, Allis (2008) ressalta a facilidade de compras de produtos, os mais variados, por conta de redução ou de eliminação de impostos, nas chamadas Duty Free. Ainda segundo o autor, por conta da legislação brasileira, esses enclaves fronteiriços oferecem esse tipo de lojas no lado estrangeiro, de forma que, ao chegar à fronteira do país vizinho, o turista brasileiro pode acessá-las facilmente - à semelhança do que acontece nas duty Free dos aeroportos internacionais. Nesse contexto, no foco da atividade do que se pode chamar 
de turismo de compras de fronteira estão a diversidade de produtos, os preços atraentes e a possibilidade de consumir produtos importados.

Allis (2008), em consonância com Lucena (2011), destaca o fato de que, nestes pontos (cidades gêmeas), a consolidação dos destinos no lado estrangeiro se dá essencialmente pela demanda brasileira, já que as facilidades e os incentivos à importação e à venda no varejo não estão disponíveis no Brasil.

Ao abordar o caso dos Free Shops que contam com a isenção de impostos de comercialização, desde que vendam apenas para estrangeiros, Dorfman (2007, p.90) expõe a percepção de um cidadão uruguaio, nos seguintes termos: "o Free Shop foi feito aqui justamente para isso, para vender para os brasileiros, porque de fato nós que vivemos aqui não podemos comprar no Free Shop, é tudo para o exterior, essa é a lei".

Neste sentido, a maior parte dos gastos deste tipo de viagem - as compras - acontece fora dos limites brasileiros. Por outro lado, as cidades brasileiras acabam oferecendo estruturas de apoio para as compras na cidade estrangeira do país vizinho. De modo geral, o fato decorre de os equipamentos de hospedagem e de alimentação apresentarem acentuada qualidade no lado brasileiro.

O grupo de pesquisa Dinâmica Configuracional e Sociedade, da Universidade Federal do Rio Grande do Sul, estudando a dinâmica de fronteiras, identificou que a cidade de Santana do Livramento - conurbada com a uruguaia Rivera, formando uma mancha urbana de cerca de 170 mil habitantes - apresenta "uma intensa atividade comercial, onde o turismo de compras e atividades de entretenimento são importantes para a dinâmica urbana atual' (RIGATTI; BRAGA; RECKZIEGEL, 2008, p.2). E, ainda:

Os serviços ligados ao turismo foram impulsionados pelo Free Shop de Rivera /UY que, nos últimos cinco anos atrai um público regional expressivo. (...). Em Rivera /UY, também ligado à agroindústria, a zona de comércio livre (Free Shop), contribui para a consolidação de novas categorias de uso comercial e para a sofisticação do comércio resultado do afluxo de turistas e da demanda por serviços entretenimento noturno e alimentação.

Em suma, as pesquisas bibliográficas realizadas apontam que a principal motivação do turismo nas cidades fronteiriças brasileiras, particularmente as cidades gêmeas, concentra-se nas facilidades de preços $e$ isenções fiscais no outro lado da linha, mas que, por vezes, se redirecionam para o lado brasileiro em termos de prestação de serviços como hospedagem e alimentação.

Se, por um lado, a autorização para a implantação de Free Shops cria uma expectativa de tornar o lado brasileiro também atrativo para a realização de compras, por outro lado, não se pode perder de vista o fato de ser fronteira. Este último fator exige o devido cuidado quanto às ações a 
serem realizadas no sentido de fortalecer as complementariedades em ambos os lados, levando-se em consideração diferentes problemáticas.

Procedimentos metodológicos

Quanto à escolha das cidades gêmeas de Corumbá - Puerto Quijarro para análise das perspectivas da Lei 12.723/2012 em relação ao turismo, esta se deu por conveniência, pois a residência e local de trabalho de maioria dos autores é nesta fronteira.

Com vistas a alcançar o objetivo proposto na pesquisa, foram realizados levantamentos de dados primários, in loco, através de entrevistas semiestruturadas, com o intuito de obter informações sobre como os agentes territoriais da fronteira Brasil/Bolívia receberam a Lei dos Free Shop.

Para tanto, foram selecionados 08 agentes territoriais que tiveram seus nomes mantidos em sigilo e identificados com a letra $E$ (Entrevistado) em uma sequência cardinal (E1; E2; E3...E-8), sendo codificados do seguinte modo: E-1: Presidente da Associação Comercial de Corumbá; E-2: Gerente de Fomento e Produção Industrial de Corumbá; E-3: Presidente do Sindicato do Comércio Varejista de Corumbá; E-4: Representante do Poder Legislativo Municipal; E-5: Representante da Receita Federal do Brasil; E-6: Gerente Geral Shopping China; E-7: Representante da Câmara de Industria, Comércio Y Servicio da Província de German Bush - Bolívia e E-8: Representante de serviço especializado em turismo de pesca de CorumbáMS.

Dentre as questões constantes nas entrevistas semiestruturadas, destacam-se: i) como receberam a publicação da Lei 12.723/2012; ii) quais devem ser as características estruturais das lojas que farão parte do Free Shop (construção de um espaço específico único ou um espaço múltiplo escolhido a critério de cada comerciante; iii) quem será o concessionário das lojas francas; iv) quais produtos deverão ser comercializados e, v) que ações já foram desenvolvidas em prol da implantação do Free Shop. Além disso, intentou-se registrar as percepções desses sujeitos quanto à seguinte questão: "Se a instalação de lojas francas trará benefícios ou prejuízos à complementariedade da fronteira Corumbá/Puerto Quijarro?"

$\mathrm{Na}$ análise dos dados, o conteúdo das entrevistas foi trabalhado a partir da observação e organização dos relatos dos agentes territoriais entrevistados, a fim de estabelecer a relação entre esse material investigado e a teoria que subsidiou o estudo.

\section{Resultados e Discussões}

Ao serem questionados a respeito da percepção que têm sobre a implantação do Free Shop, ou lojas francas, como preferem chamá-las alguns estudiosos da área, os cinco primeiros entrevistados responderam que a princípio ficaram satisfeitos com a possibilidade de adquirir equidade tributária para os empreendimentos locais. Isso porque, cotidianamente, enfrentam distorções ocasionadas pelas diferentes legislações tributárias entre os dois lados da fronteira. 
No entanto, segundo eles, a redação contida no Art. 13 da Portaria no 307, de 17 de julho de 2014 "somente poderá adquirir mercadoria de loja franca de fronteira terrestre o viajante que ingressar no País e for identificado por documentação hábil" é, no mínimo, preocupante. Os agentes entrevistados temem que a implantação de Free Shop seja atrativa apenas para os passageiros em viagens internacionais, excluindo, assim, a população fronteiriça. Uma vez que não prevê a possiblidade de compra para o fronteiriço e por não possuir fluxo contínuo de viajantes, como acontece nos aeroportos dos grandes centros, não veem o que justificaria sua implantação, pois mesmo o turismo de pesca (já consolidado) não sustentaria os investimentos devido a sua sazonalidade.

No tocante à preocupação referenciada, se o cidadão fronteiriço (brasileiro/boliviano) poderá realizar compras no Free Shop, esta mesma questão paira sobre as demais cidades gêmeas contempladas pela lei. Isso é possível de ser verificado através da entrevista que o inspetor da Receita Federal de Santana do Livramento, Sr. Adilson Valente, forneceu ao Telediário (TV 10 Rivera UY), sob o título Free Shops en Brasil: Avances em la reglamentación, quando questionado sobre a impossibilidade do morador de Santana do Livramento realizar compras no Free Shop. Segundo Valente (2015):

$\mathrm{Na}$ verdade, nós tivemos essa discussão interna, mas superamos rapidamente. Tecnicamente, se eu vou até ali do outro lado da praça (ser referindo a Rivera) eu fiz uma viagem internacional, para todos os efeitos legais, inclusive. Se eu saio daqui (Santana do Livramento/BR) atravesso a rua, eu estou em outro país que é o Uruguai, sujeito a uma ordem jurídica, inclusive, então não há como negar que eu fiz sim uma viagem internacional. Então, a gente superou essa questão presumindo que todas pessoas que forem declarar as compras tenham feito uma viagem internacional, assim os moradores (Santana do Livramento) poderão sim comprar.

Em conversa com o auditor fiscal da Receita Federal no Município de Corumbá, responsável pelo acompanhamento da implantação do Free Shop na fronteira Brasil/Bolívia, entende-se que este compartilha desse mesmo entendimento. Ou seja, "para o fronteiriço local (Corumbá) comprar, terá que comprovar com documento hábil que ele voltou dessa viagem internacional [...] a pessoa só precisa comprovar que ela fez essa viagem internacional é o que diz a legislação".

Ainda em relação à primeira pergunta, os dois agentes territoriais da Bolívia afirmaram que a implantação de Free Shop em Corumbá Ihes traz certa preocupação. A esse respeito, E-6 acredita que há pontos positivos, mas E-7 demonstra forte receio:

Há preocupação quanto à possibilidade de diminuir nossos clientes, ao mesmo tempo há a esperança que a nova 
política brasileira atraia mais pessoas para nossa fronteira, para o turismo de compra e assim amplia as possibilidades dessas pessoas desejarem conhecer a Bolívia e passar para o outro lado, sendo, portanto, clientes potenciais para lá. E6.

Esta noticia la recibimos con mucha preocupación, ya que la apertura de tiendas FREE SHOPS significaría que el comercio se concentraría en la ciudad gemela de CORUMBÁ, significando mucho más atractivo (el comercio) que en ciudades gemelas bolivianas. E-7.

Questionados a respeito de qual seria o formato ideal para as lojas francas (estrutura física), as opiniões se dividiram: 04 deles optaram pela liberdade de escolha do local onde se instalar, desde que obedecidos os critérios da Lei Municipal, pois acreditam que um espaço único para funcionamento limitaria a participação de comerciantes que não dispõem de grandes recursos para investir nesse novo formato de loja.

A esse respeito E-6 fez a seguinte afirmação: "Os Free Shops não funcionarão necessariamente em um único espaço - o município que estabelecerá o local, em Santana do Livramento, por exemplo, toda a área urbana poderá abrir empreendimento nos moldes do Free Shop". Isso demonstra seu interesse em acompanhar o andamento dos trabalhos em outras regiões de fronteira também beneficiadas pela lei. O presidente do Sindicato do Comércio varejista mencionou a possibilidade da criação de um selo de identificação para os estabelecimentos que aderirem ao regime de loja franca, assim como acontece em Rivera.

Os demais acreditam que o cliente busca comodidade, flexibilidade e proximidade entre as lojas. Além disso, "ter um espaço único para receber todas as lojas permitirá maior facilidade no controle exigido para tal modalidade" (E-4). Importante destacar o posicionamento do auditor fiscal da Receita Federal ao esclarecer:

A legislação não restringe que seja um local único - um shopping, por exemplo, a legislação não restringe que seja dessa forma. Qualquer loja que esteja hoje em funcionamento pode se tornar um Free Shop desde que tenha/ trabalhe com um único regime. Da nossa parte, claro que se estiver concentrado em um único endereço, um único local físico, facilita bastante a questão do controle e da fiscalização dessa mercadoria. Se tiver diversas lojas espalhadas pelo município a fiscalização já fica mais dificultada, mais nada que impeça que seja dessa forma. E5.

No entendimento de E-7: "todo depende cómo está escrita la ley municipal. Una combinación de ambas u otras formas, serían adecuadas 
dependiendo de las facilidades que den tanto a vendedores como a compradores. Ambas tienen sus propias características".

Em relação a quem será o comerciante/concessionário dos Free Shops, os entrevistados acreditam que a oportunidade, a priori, será para empresários da região, porém, se não houver procura, será estendida aos demais interessados, desde que cumpram todos os requisitos.

A esse respeito, E-4 frisa que seria interessante estabelecer com o país vizinho ações de cooperação para implantação do Free Shop: "quando queremos levantar um muro e não dispomos de recursos suficientes a solução é chamar o nosso vizinho e propor a construção conjunta, com o Free Shop isso não pode ser diferente". A respeito dessa assertiva, E-6 menciona que os proprietários do Shopping China aguardam término de regulamentação para verificar as vantagens para se instalar do lado de cá.

Considerando que a Portaria 307, de 17/07/2014 em seu Art. 6으, dispõe que o regime de loja franca/ Free Shop será concedido "mediante ato específico da Receita Federal do Brasil, a pessoa jurídica estabelecida no País [grifo dos autores] que atenda aos requisitos e condições estabelecidos para a sua concessão". Ao questionar E-7 se haveria interesse dos comerciantes bolivianos em se tornarem concessionários do Free Shop obteve-se a seguinte resposta:

Consideramos que el comercio es muy dinámico y no conoce fronteras; quiero decir, que El comercio trasciende fronteras y las personas dedicadas al comercio al poseer racionalidad económica, podrán asentarse en ciudades gemelas brasileñas para abrir sus tiendas Free Shops. Claro está que si cumplen todos los requisitos para abrir sus comercios. También dependerá de las condiciones establecidas en la ley de Free Shops. E-7.

Questionado sobre quem será o concessionário do Free Shop, somente comerciantes brasileiros ou estrangeiros bolivianos, E-5 acha difícil ser uma pessoa estrangeira, contudo, desde que a empresa seja estabelecida no país será permitida: "a pessoa jurídica tem que estar constituída no país, ou seja, o proprietário pode ser estrangeiro, mais a empresa tem que ser registrada no país, isto é, deve possuir um Cadastro Nacional de Pessoa Jurídica (CNPJ) no Brasil".

Quanto aos produtos que serão comercializados no Free Shop, na visão dos entrevistados, estes devem ser diversificados, diferenciados, de marcas conhecidas e disponibilizados a preços mais baixos. Em sua maioria, bebidas, perfumes, vestuários, eletrônicos, eletro portáteis, etc., "quando se tratar dos Free Shops de fronteira isso não vai mudar, pois o consumidor já sabe o que poderá encontrar nessas lojas" (E-2).

Corroborando com a afirmação de E-2, pode-se verificar que há relação com o comportamento dos consumidores, observados por Junior, Fagundes e Rossi (2011, p. 49), na cidade de Rivera: "Ios productos más consumidos son tres: bebidas, perfumes y ropa; debido al bajo precio, [...] 
queda claro que antes de ir a la ciudad de Rivera, se informaron respecto de los Duty Free Shops, de los productos y de los precios".

Para E-5, fez-se o seguinte questionamento: Existe uma lista de produtos que não deverão ser comercializados nos Free Shops, como está o andamento deste trabalho aqui em Corumbá?

\begin{abstract}
Sei que a lei (a regulamentação) permite que sejam comercializados tanto produtos estrangeiros como produtos nacionais. Claro que a questão dos produtos nacionais tem que levar em consideração também a situação do comércio local, não podemos (acredito eu) permitir que produtos muito básicos sejam vendidos nessas lojas com uma tributação diferenciada (tributação reduzida) que isso aí vai afetar diretamente o comércio local. A gente sabe que hoje os Free Shops, pelo menos os existentes atualmente em aeroportos, tem a característica de trabalhar com produtos Premium, mesmo que sejam produtos nacionais, mais produtos diferenciados [...] eu acredito que deva ficar restrito a uma lista de produtos mais diferenciados, mais isso por enquanto ainda não foi definido e nem houve uma discussão ainda em relação a isso especificamente aqui em Corumbá. E-5.
\end{abstract}

Sobre quais ações já foram desenvolvidas pela administração municipal de Corumbá em prol da implantação do Free Shop, 04 dos 08 entrevistados não souberam responder. Entre eles, E-7 menciona que desconhece qualquer ação, inclusive a de criação da lei 2.498 , de 25 de agosto de 2015 que dispõe sobre a instalação de Free Shops no município de Corumbá-MS: "todavía no conozco esta ley municipal... trataré de conseguirla para dar respuesta adecuada".

Dentre os que têm conhecimento acerca da lei municipal, estão E-2, E-3 e E-4. Este último afirmou que um dos representantes do poder legislativo já tomou a iniciativa de solicitar uma audiência pública. Entretanto, não foi realizada até o momento, devido à dificuldade de conciliar agenda entre os diversos participantes considerados imprescindíveis para discussão do assunto.

A justificativa apresentada para postergar a realização de audiência pública não coincide com a informação obtida junto a E-5 que afirma não ter sido procurado para tratar desse assunto: "não temos tido demanda, ou não temos sido procurados (digamos assim) pelos empresários locais ou pela própria administração municipal em relação a esse tema [Free Shop]". E continua:

Aqui a gente está bem tranquilo em relação à realização de audiência pública, sei de colegas nossos da fronteira com o Paraguai, Mundo Novo, Ponta Porã que lá está acontecendo uma movimentação muito maior por parte da associação comercial local, justamente porque lá afeta mais (valor quota) valor agregado do produto que é importado gera um 
interesse maior. Do empresariado aqui, no caso, a gente não tem tido muita movimentação. E-5.

A esse respeito, apreende-se que o efetivo engajamento do grupo de trabalho, instituído pelo Decreto Municipal 1.432, torna-se imprescindível para que a implantação de Free Shop em Corumbá se torne realidade, conforme depoimento de E-6:

\begin{abstract}
Vejo como um grande desafio os políticos não ficarem com a lei no papel e sim colocar em prática e creio que muito pouco está se ouvindo falar para a sociedade sobre as possibilidades de implantação de Free Shop, se as pessoas conhecessem as vantagens e a possibilidade de trazer muito mais pessoas aqui pra nossa fronteira, não só pelo turismo ecológico, mas também pelo turismo de compra que é um complemento para o turismo de pesca já consolidado aqui - colocariam em prática com maior brevidade possível ações necessárias a sua implantação.
\end{abstract}

Quanto aos benefícios que se espera dos Free Shops está, segundo $\mathrm{E}-1$, a mudança do perfil do comércio local: "os comerciantes que optarem em não aderir a lojas francas serão 'forçados' a investir em melhorias no seu próprio estabelecimento no intuito de encantar o cliente" que agora não será apenas o fronteiriço, mas, também, o turista que estiver de passagem pela cidade. Além de fortalecer o comércio local com a geração de novos empregos, reduzirá a saída de divisas do país.

Depois, segundo E-2, vem a equidade tributária, referindo-se as distorções ocasionadas pelas diferentes legislações tributárias entre os dois lados da fronteira e que são enfrentadas cotidianamente pelos empresários locais que geram desenvolvimento e empregos no município de CorumbáMS.

Ao questionar o auditor fiscal da Receita Federal de Corumbá, se haverá aqui benefícios ou prejuízos quanto à instalação de lojas francas, este apresenta a seguinte consideração:

Do ponto de vista da Receita Federal facilita bastante a fiscalização, ter um local que concentre essas mercadorias, principalmente as importadas, porque a gente pode usar controles informatizados que mantém um registro de todas as operações que forem feitas. [...] Outra questão também é a renda auferida por esse comércio, ela ficará no município. Não será renda gerada em outro país, isso para o município é importante, gera-se emprego aqui também no país e não no país vizinho, então tem esse benefício. Por outro, talvez a gente possa gerar certo desconforto com o comércio já estabelecido, que vende seu produto pagando imposto nacional, vai competir com uma loja que tem um regime de tributação diferenciado, pode ser que haja um conflito em relação ao comércio local. E-5 
Contrariamente ao posicionamento anterior, E-6 afirma: "os que se mostrarem resistentes não querem concorrência, pois terão que trabalhar e deixar de ser acomodados [...] quanto mais gente interessada em vir para cidade, mais atrativa ela será". A esse respeito tece, ainda, a seguinte consideração:

\begin{abstract}
Os políticos brasileiros conseguiram ver o que tinha que ser feito há muito tempo, porque as fronteiras do Brasil são abandonadas, é necessário políticas de implementação e desenvolvimento É necessário que elas sejam vistas como um lugar turístico, não só pro turista que vem de fora, que usa a fronteira como lugar de passagem para acessar os grandes centros como São Paulo, Rio de Janeiro, [...] os fronteiriços são pessoas que sentem/vivem a soberania do país e por isso devem ser valorizadas. O turismo de Corumbá tem condições de impulsionar as pessoas a pensar o Free Shop como potencialidade para promover o turismo de compra.
\end{abstract}

Diferente do posicionamento de E-6, quando observa que há pontos positivos para o lado boliviano da fronteira, E-7 acredita que só haverá perdas/prejuízos. Para ele, o Tratado de Roboré - convênio de trânsito livre assinado entre o Brasil e a Bolívia, em 29 de março de 1958, na cidade de La Paz, que dispõe sobre práticas comerciais, bem como de circulação de mercadorias entre ambos os países - não é respeitado por autoridades fronteiriças brasileiras. Uma vez que, de acordo com esse convênio fronteiriço de 29/03/1958, os bolivianos e os brasileiros poderiam comprar em ambas as cidades gêmeas "hasta 3.000 cruceiros por semana o su equivalente enmoneda boliviana (Artículo IV del Convenio de Tráfico Fronterizo; enlamoneda y poder adquisitivo de esa época". Acrescenta ainda que:

La implementación de Free Shop traerá perjuicios a nosotros como sus más cercanos vecinos, pues la mercadería que salga de estas tiendas serán más competitivas que en Bolivia, por lo tanto generarán corrientes fuertes de comerciantes que quieran comprar de estas tiendas. Por otro lado Brasil debe tomar en cuenta los tratados que se tiene firmado con Bolivia, por ejemplo: El Tratado de Roboré de 29 de marzo 1958, El Convenio Fronterizo de 29 de marzo 1958 e El Tratado Del MERCOSUR que entrará en vigencia una vez Bolivia sea aceptada como miembro pleno Del MERCOSUR. El Tratado de Roboré no es respetado principalmente por autoridades fronterizas brasileñas, lo que demuestra, de inicio, un aspectos desventajoso para Bolivia.

De acordo com E-7, uma solução para esse impasse seria a atualização desses valores: "proporcionar el tipo de cambio de marzo 1958 entre el Real y el dólar, así podremos conocer, en términos de intercambio, cuánto significaba los 3.000 cruceiros, o cual era su valor adquisitivo". 
Embora a desvantagem apontada por E-7 não esteja relacionada somente ao artigo 22 da portaria no 307/2014 que versa sobre 0 artigo $7^{\circ}$ da Portaria $n^{\circ} 440 / 2010$ reduzindo o limite dos gastos no exterior - de US\$300 para US\$ 150 - com isenção de Imposto de Importação, aplicada nas fronteiras terrestres do país, o cenário que se vislumbra para as interações na fronteira Brasil/Bolívia parece conflituoso.

De acordo com Fernandes (2015), a medida é um retrocesso para o comércio fronteiriço na Zona de Fronteira Brasil/Bolívia, pois as cotas continuarão assimétricas:

O consumo por via terrestre no lado boliviano da fronteira, sem tributação, será de até US\$150,00 a partir de julho de 2015. No lado brasileiro, o boliviano poderá gastar até US\$ 1.000,00. Deste modo, a Receita Federal ao publicar as portarias $n^{\circ} 307 / 2014$ e $n^{\circ}$ 320/2014 mais uma vez desconsiderou as dessemelhanças da extensa faixa de fronteira terrestre brasileira, as distintas complementariedades comerciais/cotidianas entre os fronteiriços, especialmente da Zona de Fronteira em discussão (FERNANDES, 2015, p. 196).

No caso da fronteira Brasil/Bolívia, Fernandes (2015, p.5) afirma que "está se institucionalizando um cenário que a priori favorece o comerciante brasileiro e o consumo nas cidades brasileiras (algo que já se ensaiava com a Portaria 440/2010)". E ainda conclui:

Teoricamente as restrições quantitativas para os bolivianos somarão US\$1.300,00. Este valor corresponde aos US\$ $1.000,00$ estabelecidos no artigo 188 do "Reglamento a la Ley General de Aduanas", dispositivo que regula a margem de compra individual, com isenção, do cidadão boliviano no exterior e ao limite estabelecido pela Portaria $n=307 / 2014$ de US $\$ 300,00$ nas Lojas Francas que serão instaladas no lado brasileiro da fronteira, caso queira consumir em tais estabelecimentos. Em contrapartida, o brasileiro poderá consumir em Puerto Quijarro ou Puerto Suarez, sem tributação, a quantia de US\$150,00 (FERNANDES, 2015, p. $5)$.

$\mathrm{Na}$ esfera estatal, existe a necessidade de ações políticas que venham descentralizar a tomada de decisão que, por vezes, não leva em consideração a dinâmica e as especificidades locais de região de fronteira, causando entraves ao desenvolvimento dessas regiões. Cabe ao grupo de trabalho, que inclusive define como integrante um representante da Receita Federal, reunir esforços no sentido de pontuar essa questão deixando claramente definido os prejuízos que a redução da cota, caso mantida, trará para as fronteiras em questão. É o que pontua E-5:

Acredito que um grupo de trabalho multidisciplinar que envolva pessoas que estão ligadas a esse processo é 
justamente importante para se ter a visão de todos os agentes. Uma visão macro, porque nós, enquanto agentes arrecadadores e de fiscalização, temos a nossa visão, mas é sempre bom ouvir também o que se passa com outros envolvidos, justamente para definir essas questões que estão em aberto na legislação e trazer isso para o caso concreto [...] O grupo de trabalho pode com certeza contribuir muito para que a gente possa definir esses detalhes da legislação específicos pra essa região, para característica local dessa fronteira Brasil/Bolívia.

Ao se referir à entrada em vigência da cota reduzida, E-5 acredita que como não se tem notícia de que a regulamentação das lojas francas ocorrerá até o meio do ano, a partir de 01/07/2016 (conforme previsto pela Portaria 415, de 26/06/2015), a nova cota (US\$150) se efetivará, mesmo sem implantação das lojas francas, sendo que "[...] para nossa fronteira a questão da cota não afeta muito as importações", pontua.

Isso porque, segundo ele, o que se tem observado na fiscalização dessa fronteira é que a cota em valor financeiro não é atingida com muita frequência, o que acaba realmente impedindo/restringindo a entrada de mercadorias importadas é a cota em unidades físicas: "a nossa fronteira não será muito afetada por isso, mais também a gente pensou que esse seria um fator de pressão para que a gente regularizasse logo as lojas francas" (E5).

O fato da opinião do auditor fiscal da Receita Federal em relação à redução da cota ser contrária a dos comerciantes que participaram da mobilização nas fronteiras Brasil/Bolívia e Brasil/Paraguai, remete a uma necessidade já apontada por Fernandes (2015, p.12): o efetivo envolvimento do grupo de trabalho para "realização de reuniões participativas que possibilitem a aproximação da pluralidade de ideias dos cidadãos interessados no assunto com a concepção técnica dos órgãos de planejamento".

Dessa forma, o empenho desse grupo em apresentar informações que tratam das particularidades do território, que não são poucas, auxiliaria a Receita Federal e os gestores municipais na realização das adequações normativas pertinentes.

A respeito da preocupação quanto ao trâmite necessário para atender o cliente que ultrapassar a cota, o auditor da Receita Federal presta o seguinte esclarecimento:

Acredito que não será nada que vá gerar muita dificuldade, se está havendo essa flexibilidade na legislação para permitir a instalação dessas lojas. A ideia é que seja bem simples, bem dinâmico, porque o comércio depende desse dinamismo para concluir seus negócios. Se a pessoa tem aquele impulso da compra e chega ao momento de pagar tem uma série de empecilhos, talvez até desista da compra; isso não é a intenção. A intenção é fomentar o comércio desde que haja 0 recolhimento dos tributos devidos 
corretamente. Acredito que não haverá esse tipo de empecilho.

Quanto à questão de complementariedade da fronteira, durante trabalho de campo, ao perguntar para E-8 se as compras na Bolívia fazem sempre parte de seu roteiro, sua resposta foi sim, tanto que dispõe de um micro-ônibus para essa finalidade: "o grupo já chega aqui com a ideia de dar um 'pulinho' lá na Bolívia para passear, já veem um perfume para a esposa, um souvenir (...)". E ainda acrescenta:

O passeio na Bolívia normalmente dura de 3 a 4 horas. Eles saem, passam na feirinha, aí passam na Miami House, passam lá na zona franca e vem embora. Esse normalmente é o roteiro de compras deles. Com certeza $99 \%$ dos nossos clientes faz esse roteiro. [...] Mesmo com a cotação do dólar em alta eles continuam indo para lá, ainda que não comprem, querem ir para lá pela questão cultural.

Esses pontos de vistas conduzem à reflexão de que as ações para implantação do Free Shop em Corumbá, MS, ou qualquer outra cidade gêmea de fronteira devem ser formatadas considerando a interação já existente. A proximidade com o outro lado desperta no turista/visitante a curiosidade em saber como é a cultura do país vizinho, além de informações quanto ao preço lá praticado e se os produtos são similares. Com o Free Shop em Corumbá, certamente haverá comparação entre quem oferecerá a maior vantagem em relação a custo-benefício, antes de decidir a compra.

\section{Considerações finais}

O fato de uma pessoa - turista/visitante/residente - cruzar o limite entre um território fronteiriço constitui-se, tecnicamente, numa ação que se caracteriza como uma viagem internacional. Uma vez que plasma a peculiaridade citada, qualquer fronteiriço, visitante e/ou turista que se mobiliza por cidade gêmea brasileira - a exemplo de Corumbá, MS - poderá comprar no Free Shop. É essencial, pois, que a legislação brasileira, por meio de regulamentação específica, preveja qual será, de fato, a documentação (hábil) que abarcará a identificação desse viajante e como isso se efetivará.

Partindo desse pressuposto, o comércio poderá ser compreendido como uma atividade dinâmica que não conhece fronteiras. Em vista disso, os agentes fronteiriços do lado estrangeiro poderão se apropriar da condição de complementariedade dessa fronteira para o desenvolvimento do potencial turístico boliviano, no uso do Free Shop como um atrativo a mais. Ou, dizendo de outro modo, poderá vender o lado brasileiro a partir da sua fronteira, assim como fazem os operadores turísticos do Brasil em seus pacotes.

Isto posto porque, caso não sejam consideradas as interações presentes no cotidiano dos territórios fronteiriços, haverá impactos negativos na implantação do Free Shop, conforme observado na pesquisa realizada 
em Corumbá, MS. Em contrapartida, o estabelecimento de um Free Shop poderá tornar o lado brasileiro da fronteira mais competitivo, dada a geração de empregos e a atração turística. Isso não inibirá as visitações ao outro lado fronteiriço. Nesse contexto, os empresários poderão aproveitar as oportunidades da fronteira de modo mais criativo.

É fato aceito que a chave para produzir um desenvolvimento territorial harmonioso é o estreitamento das relações de complementariedades comerciais fortemente presentes nesse cotidiano fronteiriço. Isto é, tornar os agentes territoriais do país vizinho integrantes do grupo de trabalho responsável por organizar as ações necessárias à implantação do Free Shop. A união das forças desses agentes fará com que a singularidade desse território seja levada em consideração.

Por fim, cabe dizer que a implantação do Free Shop nas cidades gêmeas, conforme já apresentado pela pesquisa desenvolvida em Corumbá, pode trazer acentuados benefícios para o turismo nos territórios de fronteira, desde que sua construção seja dialogada, de modo a tornar evidentes as possibilidades de desenvolvimento econômico para as cidades componentes dessa fronteira. Pode-se destacar a atração de novos investidores, gerando trabalho e renda, a agregação de valor às atividades turísticas (de pesca, aventura, eventos), pois as pessoas, além de virem a passeio, aproveitarão a ocasião para compras de produtos com preços mais atrativos.

\section{Referências}

ALLIS, T. Considerações sobre turismo de compras nas fronteiras brasileiras. O caso de Pacaraima (RR) e Santa Elena de Uairén (Venezuela). Anais... Seminário de Pesquisa em Turismo do MERCOSUL. Caxias do Sul, RS, Brasil, 2008.

AMARAL, J.H.F. Feira dos Importados com produto turístico de Brasília. ERevista Facitec, v.2, n.2, Art.6, dezembro, 2008.

ALVES, E.L.P; FERRAZ, G.A.V.; OLIVEIRA, M.A.M. O Turismo e a Fronteira, uma breve discussão. In: COSTA, G.V.L.; OLIVEIRA, M.A.M.; SIQUEIRA, K.M. (Orgs.). Fronteiras: Conflitos, Integração e Políticas Públicas. Campo Grande, MS: Ed. UFMS, 2011.

BANDUCCI Junior, A. Turismo e fronteira: integração cultural e tensões identitárias na divisa do Brasil com o Paraguai, PASOS. Revista de Turismo y Patrimonio Cultural, v.9, n.3. Special Issue. 2011.

BELTRÃO, O. Turismo: a indústria do século 21. 1. ed. Lorena: Stiliano.1999.

BRASIL. Lei $n^{\circ}$ 12.723, de 9 de outubro de 2012. Diário Oficial da República Federativa do Brasil. Brasília: DOU, 10 de outubro de 2012.

BRASIL. Ministério da Fazenda. Portaria MF no 307 de 17 de julho de 2014. Dispõe sobre a aplicação do regime aduaneiro especial de loja franca em fronteira terrestre e altera a Portaria MF n 440, de 30/07/2010. Brasília, 2014. 
BRASIL. Ministério da Fazenda. Portaria MF no 320, de 22 de julho de 2014. Dispõe sobre a aplicação do regime aduaneiro especial de loja franca em fronteira terrestre e altera a Portaria MF № 440, de 30/07/2010. Brasília, 2014.

BRASIL. Ministério da Fazenda. Portaria MF no 415, de 26 de junho de 2015. Altera a Portaria MF $\mathrm{n}=307$, de 17/07/2014, que dispõe sobre a aplicação do regime aduaneiro especial de loja franca em fronteira e o tratamento tributário relativo a bens de viajante. Brasília, 2015.

BRASIL. MINISTÉRIO DA INTEGRAÇÃO NACIONAL. Programa de Promoção do Desenvolvimento da Faixa de Fronteira - PDFF. Secretaria de Programas Regionais. Governo Federal. Brasília, 2009b. Disponível em Acesso em 05 de agosto de 2009.

CASTELLO, I.R. Áreas de Fronteira: territórios de integração, espaços culturalmente identificados? In.: CASTELLO, I.R. et al. (org.). Práticas de Integração nas Fronteiras: temas para o MERCOSUL. Porto Alegre: Ed. da Universidade / UFRGS, Instituto Goethe / ICBA, 1995.

CASTROGIOVANNI, A.C.; GASTAL, S. Fronteiras e Turismo: tensionando conceitos. In: Seminário de Pesquisa em Turismo do Mercosul e Seminário da Associação Nacional de Pesquisa e Pós-Graduação em Turismo, 2006, Caxias do Sul. Anais. Caxias do Sul: Educs, 2006.

CASTROGIOVANNI, A.C.; GASTAL, S. Turismo x Espaço: reflexões necessárias na pós-modernidade. In: GASTAL, S.; CASTROGIOVANNI, A.C. (orgs.). Turismo na Pós-Modernidade: (des)inquietações. Porto Alegre: EDIPUCRS, 2003. (Coleção Comunicação, 25).

CORIOLANO, L.N.M.T.; SILVA, S.C.B.M. Turismo e geografia: abordagens críticas. Fortaleza: UEC, 2005.

CORUMBÁ. Decreto no 1.432, de 21 de outubro de 2014. Dispõe sobre a criação do Grupo de Trabalho para discussão, organização e criação do Plano de Ação para Implementação de Loja Franca em Fronteira terrestre. Publicado no Diário Oficial em 22/10/2014.

CORUMBÁ. Lei no 2.498, de 25 de Agosto de 2015. Dispõe sobre a instalação de lojas Free Shops no Município de Corumbá-MS como mecanismo de desenvolvimento local e regional. Publicado no Diário Oficial em 25/08/2015.

COSTA, L.C.N. Turismo e paisagem cultural: para pensar o transfronteiriço. 2011. 190 f. Dissertação (Mestrado) - Universidade de Caxias do Sul, Programa de Pós-Graduação em Turismo, 2011.

COSTA, E.A. Ordenamento territorial em áreas de fronteira. In: OLIVEIRA, M.A.M. (Org.). Seminário de estudos fronteiriços. 1. ed. Editora da UFMS, Campo Grande, 2009.

COSTA, E.A. Mexe com o que? Vai pra onde? Constrangimentos de ser fronteiriço. In: Costa, E.A.; Costa, G.V.L; Oliveira, M.A.M. (Org.). Fronteiras em foco. 1ed. v. 1, Editora da UFMS, Campo Grande, 2011. p. 131-147. 
COSTA, E.A.; FIGUEIREDO, N.P.; SILVA, A. Fronteira: limite ou potencialidade para as práticas do turismo? Anais... II Seminário de Estudos Fronteiriços. MS: ed. UFMS, Corumbá, 2010.

DALLABRIDA, V.R. A gestão social dos territórios nos processos de desenvolvimento territorial: uma aproximação conceitual. Sociedade, Contabilidade e Gestão, v.2, n2, Rio de Janeiro, 2007.

DIAS, R. Introdução ao turismo. São Paulo: Atlas, 2005.

DORFMAN, A. Fronteira e contrabando em Santana do Livramento (BR)Rivera (UY). Boletim Gaúcho de Geografia, v. 32, n. 1, 2011.

FERNANDES, R.M.S. Cotidiano fronteiriço versus deliberações de estado: aniquilamento de classe e desentrosamento (s) de governança na zona de fronteira Brasil/Bolívia. Revista Pegada, v. 16, n. 1, 2015.

JUNIOR, P.C.; FAGUNDES, T.M.; ROSSI, C. Satisfacción y valoración del consumidor en relación al turismo de compras en la ciudad de RiveraUruguay. Estudios y perspectivas en turismo, v. 20, n. 1, p. 34-56, 2011.

HAESBAERT, R. Território e Multiterritorialidade: um debate. GEOgraphia, ano IX, n.17, p.19-46, 2007.

LEITE, N.K. Turismo e Território: Um estudo sobre a Turistificação de Portimão (Algarve/Portugal) a partir da Geografia do Turismo. 2008. Tese (Doutorado).

LUCENA, M.G. Territorialidade de fronteira: uma contribuição ao estudo da questão fronteiriça Brasil-Uruguai no contexto MERCOSUL. Universidade Rural do Rio de Janeiro - RJ, 2011. Tese (Doutorado em Ciências Humanas e Sociais).

MARIANI, M.A.P.; ARRUDA, D.O. Território, territorialidades e desenvolvimento local: um estudo de caso dos empreendimentos econômicos solidários de Corumbá/MS. In: 48ํㅡㄹ Congresso da Sociedade Brasileira de Economia, Administração e Sociologia Rural-SOBER. Anais... Campo Grande, MS, 2010.

MARIANI, M.A.; FISCHER, R.M. As territorialidades de Empreendimentos Econômicos Solidários (EES) no contexto de um sistema produtivo do turismo: um estudo de caso em Corumbá (MS). Revista Brasileira de Ecoturismo, v.7, n.2, pp.412-433, São Paulo, 2012.

OLIVEIRA, T.C.M. Tipologia das relações fronteiriças: elementos para 0 debate teórico-prático. In: OLIVEIRA, T.C.M. (org.) Território sem limites: estudos sobre fronteira. Editora UFMS, p.377- 408, Campo Grande, 2005.

OLIVEIRA, T.C.M. Os elos da integração: o exemplo da fronteira BrasilBolívia. In: OLIVEIRA, M. A. M; COSTA, E. A. (Orgs). Seminário de estudos fronteiriços. 1. ed. Editora da UFMS, Campo Grande, 2009.

PAIXÃO, R.O. Turismo na Fronteira, identidade e planejamento de uma região. Série Fontes Novas. Ed. UFMS, Campo Grande-MS, 2006. 
RIGATTI, D.; BRAGA, A.C.; RICKZIEGL, D. Categorias de comércio na fronteira sul do Brasil. Santana do Livramento/BR e Rivera/UY. Anais... II Colóquio Internacional sobre comércio e cidades: uma relação de origem. São Paulo, 2008.

SACK, R. Human territoriality: its theory and history. Cambridge: Cambridge University Press, 1986.

SAQUET, M.A. Abordagens e concepções sobre território. $3^{\text {a }}$ ed. São Paulo: Outras Expressões, 2013.

SOFIELD, T.H.B. Border Tourism and Border Communities: An Overview. Tourism Geographies, Vol. 8, n.2, 2006, p. 102-121.

VALENTE, A.J. Receita Federal Santana do Livramento. TV10RiveraUY Disponível em: https://www.youtube.com/watch?v=jMy5UWV-Uks. Acesso em fevereiro de 2016.

Rosa Barros Ferreira Almeida: Universidade Federal de Mato Grosso do Sul, Campos Grande, MS, Brasil.

E-mail: rbf_almeida@hotmail.com

Link para o currículo Lattes: http://lattes.cnpq.br/6421152116801925

Edgar Aparecido da Costa: Universidade Federal de Mato Grosso do Sul, Campos Grande, MS, Brasil.

E-mail: edgarac10@gmail.com

Link para o currículo Lattes: http://lattes.cnpq.br/3166411825044548

Milton Augusto Pasquotto Mariani: Universidade Federal de Mato Grosso do Sul, Campos Grande, MS, Brasil.

E-mail: miltmari@terra.com.br

Link para o currículo Lattes: http://lattes.cnpq.br/0935409945176042

Alejandro Gabriel Benedetti: Universidad de Buenos Aires, Buenos Aires, Argentina.

E-mail: alejandrobenedetti@conicet.gov.ar

Link para o currículo Lattes: http://lattes.cnpq.br/0821756529449510

Data de submissão: 09 de maio de 2017

Data de recebimento de correções: 12 de junho de 2017

Data do aceite: 12 de junho de 2017

Avaliado anonimamente 